\title{
Clinical Results of a Brindley Procedure: Sacral Anterior Root Stimulation in Combination with a Rhizotomy of the Dorsal Roots
}

\author{
F. M. J. Martens and J. P. F. A. Heesakkers \\ Department of Urology (659), Radboud University Nijmegen Medical Centre, P. O. Box 9101, 6500 HB Nijmegen, The Netherlands
}

Correspondence should be addressed to F. M. J. Martens, f.martens@uro.umcn.nl

Received 28 February 2011; Accepted 14 April 2011

Academic Editor: Francisco Cruz

Copyright ( $) 2011$ F. M. J. Martens and J. P. F. A. Heesakkers. This is an open access article distributed under the Creative Commons Attribution License, which permits unrestricted use, distribution, and reproduction in any medium, provided the original work is properly cited.

The Brindley procedure consists of a stimulator for sacral anterior-root stimulation and a rhizotomy of the dorsal sacral roots to abolish neurogenic detrusor overactivity. Stimulation of the sacral anterior roots enables micturition, defecation, and erections. This overview discusses the technique, selection of patients and clinical results of the Brindley procedure. The Brindley procedure is suitable for a selected group of patients with complete spinal cord injury and detrusor overactivity. Overall, the Brindley procedure shows good clinical results and improves quality of life. However, to remain a valuable treatment option for the future, the technique needs some adequate changes to enable analysis of the implanted parts, to improve revision techniques of the implanted parts, and to abolish the sacral dorsal rhizotomy.

\section{Introduction}

The Brindley procedure consists of a stimulator for sacral anterior-root stimulation (SARS) and a rhizotomy of the dorsal sacral roots to abolish neurogenic detrusor overactivity. Stimulation of the sacral anterior roots enables micturition, defecation, and erections. The Brindley procedure is suitable for a selected group of skeletally mature patients with complete spinal cord injury and detrusor overactivity, who do not respond adequately to conservative treatments of the detrusor overactivity. Patients with severe autonomic dysreflexia or detrusor-external sphincter dyssynergia will benefit especially from the dorsal rhizotomy. Patients with incomplete injury will lose their sensory function due to the dorsal rhizotomy and have the risk to experience pain sensation during stimulation due to an incomplete rhizotomy. The technique, selection of patients, and clinical results are discussed in this overview.

\section{Brindley Stimulator}

The Brindley system is composed of an external and implanted part. The implanted part consists of electrodes, connecting cables, and a receiver block. Patients have to position an external stimulating device on the skin over the implanted receiver to evoke stimuli. The receiver does not have a battery. Electrical stimuli are evoked by radiofrequency waves. With the availability of separate stimulation of the sacral levels and various stimulation settings, it is possible to set various stimulation programs to optimize micturition, defecation, and penile erections.

A tripolar electrode cuff is used for intradural stimulation of the sacral anterior roots. A three-channel implant is composed of two books. The upper book contains three parallel slots for S3 (one slot) and S2 roots (two slots at one channel), and the lower contains one slot for S4 roots. Each slot contains one cathode in the centre and an anode at each of the two ends to avoid stimulation of tissue structures outside the slot. The two-channel implant allows stimulation of two root levels or sets of root levels. The four-channel implant has the same configuration as the three-channel implant but allows independent stimulation of four sets of roots. The choice for the number of channels depends on the number of different rootlet combinations that have to be stimulated. Each channel is connected to the subcutaneous receiver block by a silicone-coated cable. 
Extradural electrodes are used in patients in whom intradural electrodes could not be placed due to, for example, arachnoiditis or a previous intradural electrode implantation that failed. Some centres prefer to use extradural electrodes primarily for nearly all patients. The extradural implant has three helical electrodes at its end, which are also configured with a cathode between two anodes.

\section{Poststimulus Voiding}

Most of the small diameter parasympathetic efferent nerve fibres for innervation of the bladder are located in the sacral anterior roots (S2-S4/5). Small-diameter nerve fibres need a higher stimulus for their excitation than large-diameter fibres. Consequently, electrical stimulation of the anterior roots for detrusor contractions also causes contraction of the urethral sphincter due to stimulation of somatic largediameter nerve fibres. This prevents emptying of the bladder. To overcome this problem, poststimulus voiding is used. The time to relax of striated muscles of the urethral sphincter is shorter than the relaxation time of smooth muscles of the detrusor. When intermittent stimulation pulse trains are applied, the difference in muscle relaxation time can be used to achieve a sustained detrusor muscle contraction with intervals of urethral sphincter relaxation (Figure 1). These intervals in between stimulations allow a decrease of the urethral sphincter pressure while a high intravesical pressure remains. This results in poststimulus voiding with an intermittent pattern of the micturition flow. A comparable mechanism has been used for defecation.

\section{Dorsal Rhizotomy of the Sacral Nerves}

Sauerwein structurally expanded SARS with a dorsal rhizotomy (deafferentation) of sacral roots S2 till S5 [1]. A dorsal rhizotomy is important because it suppresses neurogenic detrusor overactivity and detrusor-external sphincter dyssynergia $[1,2]$. This results in a low-pressure bladder without reflex contractions of the detrusor and subsequently continence. Moreover, it reduces autonomic dysreflexia [2, 3]. Therefore, a dorsal rhizotomy can also be applied in combination with intermittent catheterization to empty the bladder without implantation of a Brindley stimulator [3].

\section{Patient Selection}

Patients need to have intact efferent nerve pathways to the bladder and a bladder that is able to contract. Contractions of at least $50 \mathrm{~cm} \mathrm{H}_{2} \mathrm{O}$ in males or $30 \mathrm{~cm} \mathrm{H}_{2} \mathrm{O}$ in females need to be present during filling cystometry [4]. If no sufficient spontaneous contraction occurs, suitable patients can be selected by rectal stimulation according to electroejaculation procedures or direct needle stimulation of the sacral roots to provoke bladder contractions.

Preoperative magnetic resonance imaging is used to exclude arachnoiditis at the level of the conus and cauda equine or other neurological disorder of the spinal cord.
Patients with active or previous arachnoiditis are not suitable for intradural electrode implantation.

\section{Implantation}

A laminectomy from L3-L4 to S1-S2 is done for an intradural rhizotomy and intradural implantation of the electrode cuff. The dura and arachnoid are opened at midline to expose the sacral nerve roots. The anterior and dorsal components of the roots, especially relevant anterior roots for micturition, can be identified intradurally by electrical stimulation of these components while monitoring the effects on detrusor activity, blood pressure, and somatomotor responses. A rhizotomy of the identified dorsal sacral roots is done. The anterior sacral roots are positioned into the electrode cuff. The connecting cables are subcutaneously tunnelled to a subcutaneous pocket for the receiver.

Implantation of extradural electrodes requires a laminectomy from L5-S1 to S3-S4. The dorsal rhizotomy is done at the level of the ganglia of S2-S5. Electrical stimulation tests are used to identify the anterior and dorsal components of the sacral roots. The extradural electrode is implanted and fixated to the nerve using a strip of silicone rubber sheet which is sewn to itself and surrounds the nerve. The connecting cables and the receiver are implanted the same way as the intradural procedure.

\section{Clinical Results}

Table 1 shows an overview of publications on the clinical results of the Brindley procedure [3-20]. These results comprise both the Brindley stimulator, which enables stimulation for micturition, defecation, and erections, and the dorsal rhizotomy to achieve continence. The use of the Brindley procedure for micturition and defecation, and the ability to evoke erections are summarised in Figure 2, including urinary continence rates. No accumulation of results is possible due to the overlap of results of several reports, especially the multicentre reports.

The Brindley stimulator is used for micturition in $73 \%$ to $100 \%$ of patients during followup. These are considerable percentages, but it should be noted that this includes patients who use additional methods to empty their bladder. Additional methods comprise intermittent catheterization, abdominal straining (Valsalva manoeuvre), abdominal compression (Credé manoeuvre), or suprapubic tapping for reflex contractions. Stimulation that is not always completely successful can be found back in the percentages of patients that have less than $50 \mathrm{~mL}$ residual urine after stimulation for micturition. These percentages are lower than the percentages of patients that use the stimulator for micturition. Overall, the percentages of patients having urinary tract infections and the frequency of urinary tract infections decrease after the Brindley procedure compared to the preoperative treatment.

The Brindley stimulator is used for defecation in $29 \%$ to $100 \%$ of patients in different degrees. Not all patients achieve complete evacuation of defecation using only stimulation. 


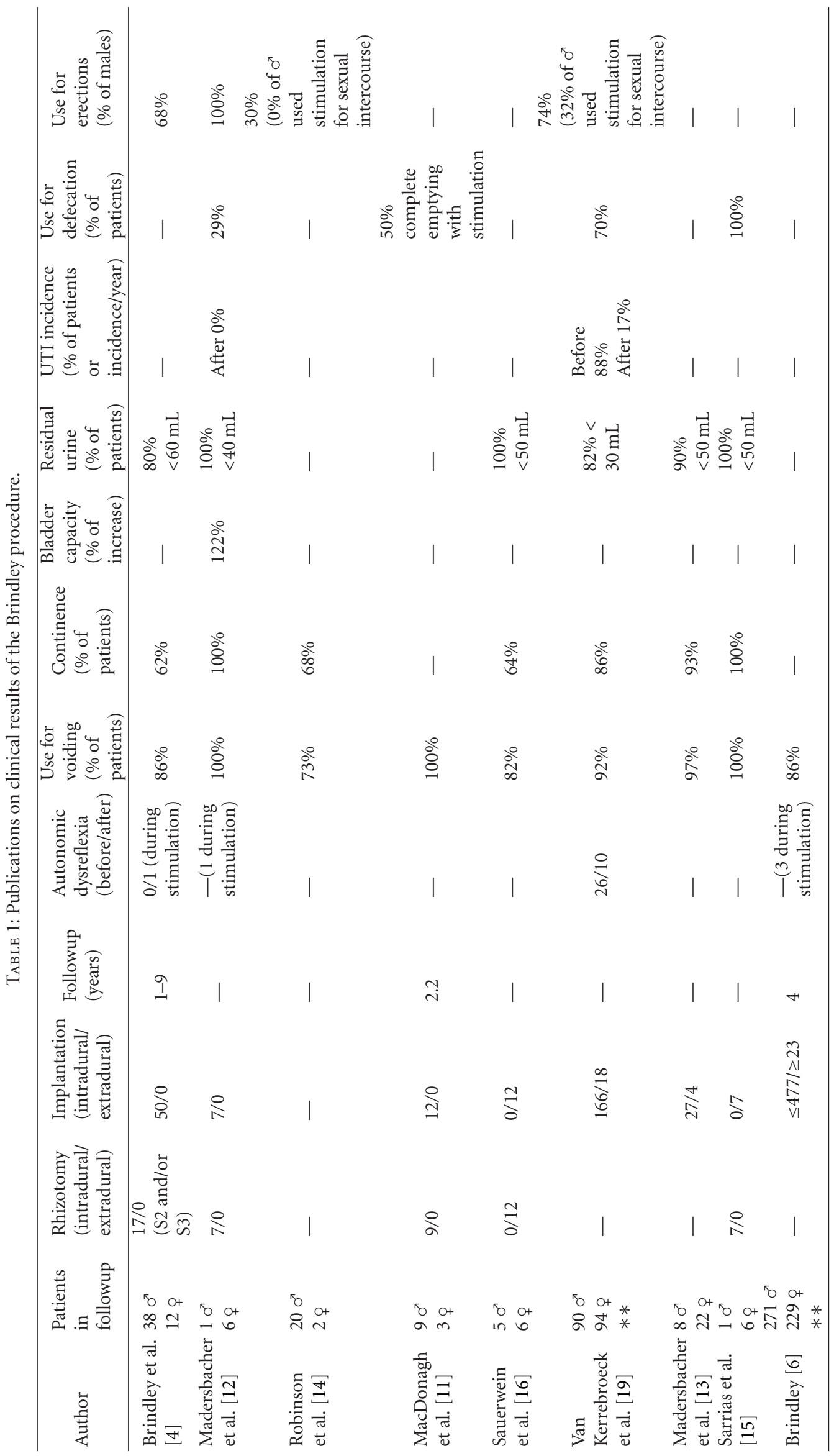




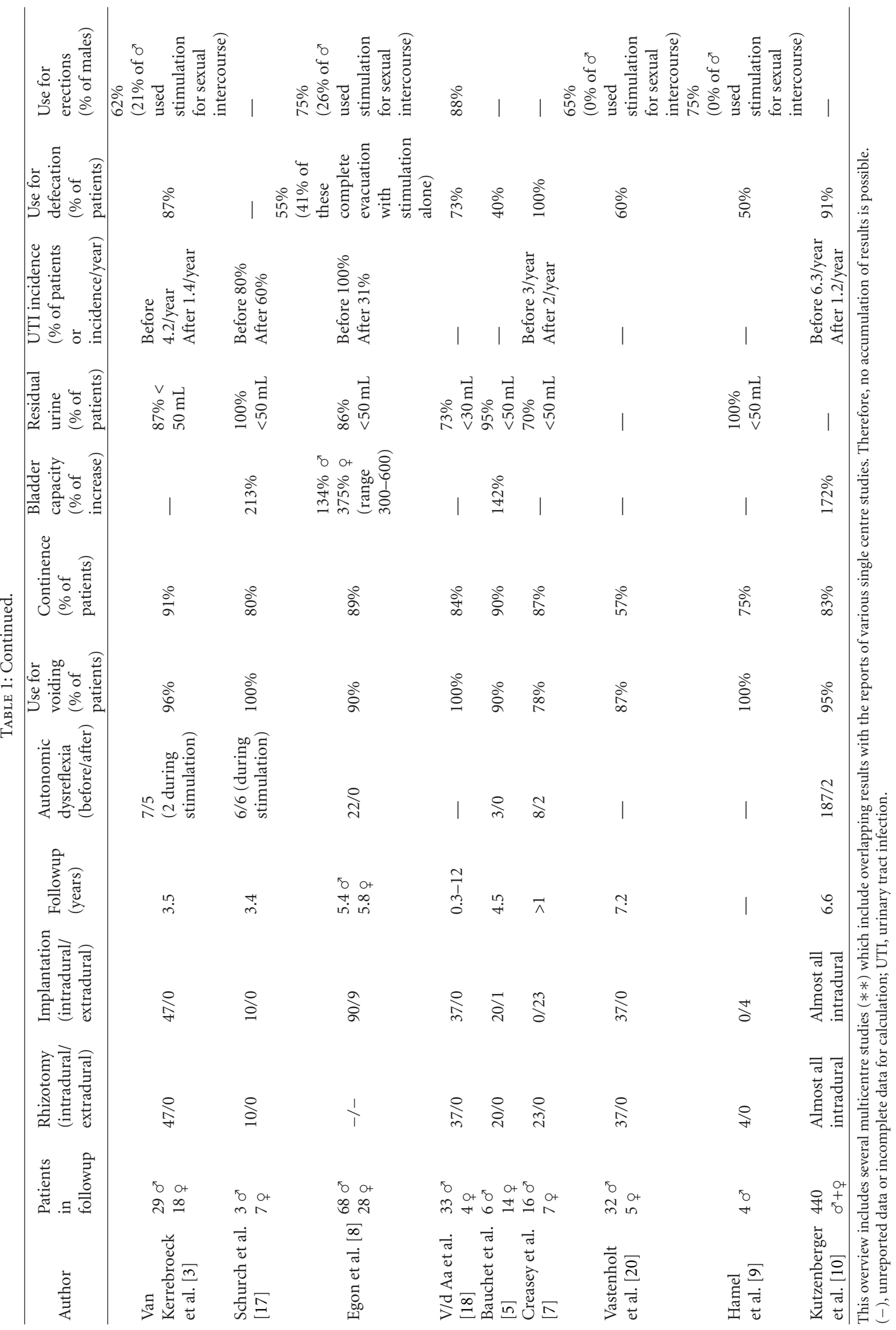




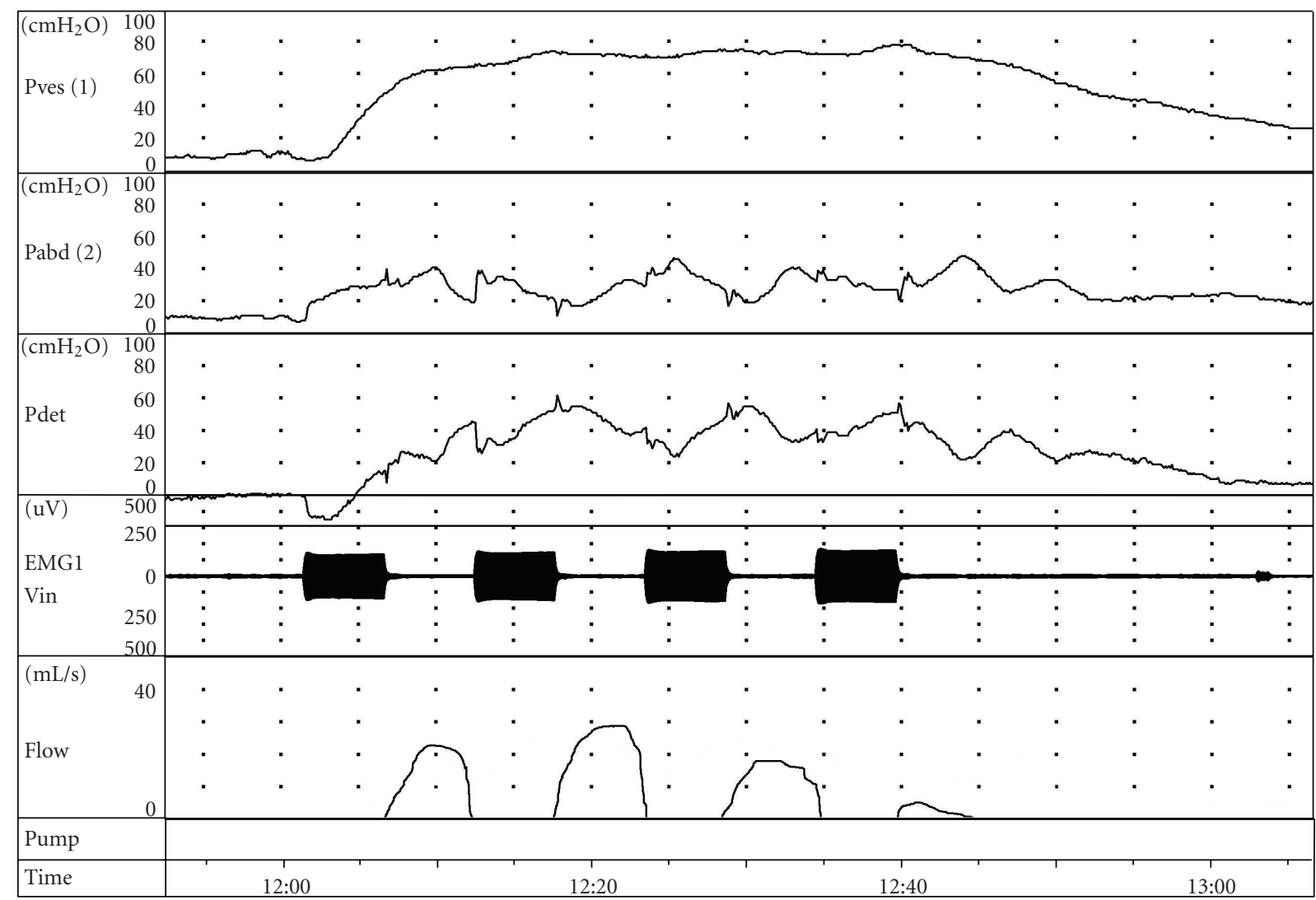

FIGURE 1: Example of poststimulus voiding using a Brindley stimulator. The three upper traces show the intravesical (Pves), intra-abdominal (Pabd), and detrusor (Pdet) pressures during stimulation with a Brindley stimulator. The increase in EMG signal reflects the activation of the stimulus during 5 seconds. Stimulation is activated every 12 seconds. The intermittent stimulation pattern allows the urethral sphincter to relax while the detrusor pressure remains elevated. This results in an intermittent flow pattern.

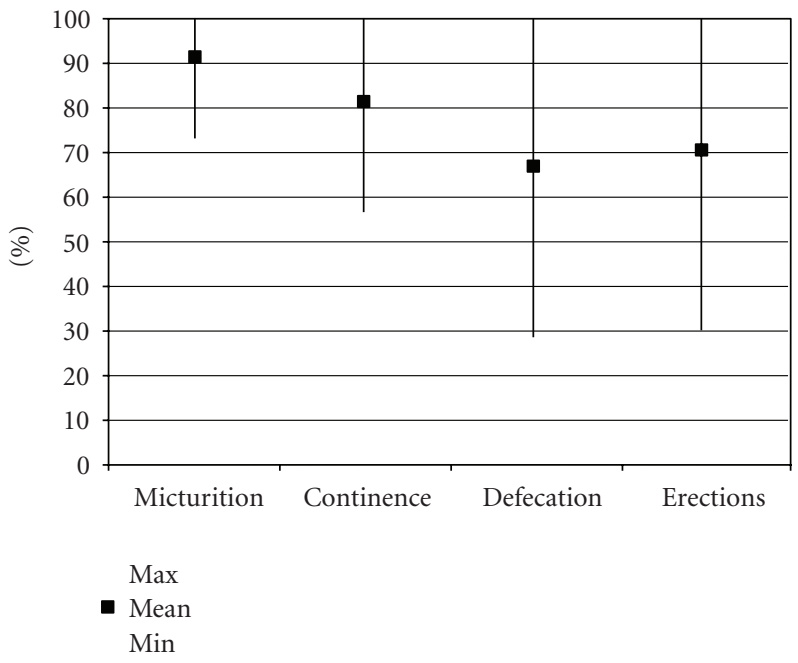

FIgURE 2: Results of the Brindley procedure on micturition, continence, defecation, and erections are summarised.

Some patients need laxatives in addition to prevent constipation or enable defecation. Many patients only use the stimulator to get the defecation into the rectum, to enable digital evacuation.
Erections can be evoked in a substantial number of patients, but results vary considerably. This can be explained by the relatively low number of patients that actually use the stimulator to evoke erections for sexual intercourse (0$32 \%)$, due to qualitatively inadequate erections for sexual intercourse or deterioration of the stimulation effect over time.

Autonomic dysreflexia mostly decreased after the Brindley procedure as a result of the dorsal rhizotomy. Only a few studies reported stimulation-induced autonomic dysreflexia.

Continence is achieved in $57 \%$ to $100 \%$ of patients, and bladder capacity increased. However, continence is not only achieved by a dorsal rhizotomy. Results on continence also included additional treatments, like anticholinergics and stress incontinence surgery.

\section{Discussion}

The ultimate treatment of neurogenic disorders of the lower urinary tract would be resolvement of the neurogenic disorder that causes the bladder problems to restore the innervation of the bladder. As long as this causal treatment is not available, symptomatic treatment options are required. 
Intravesical Botulinum toxin A injections are an evolving option in the current treatment arsenal. At the time when this paper was written, approval for urological application was expected within short time. However, the Brindley procedure has several advantages for suitable patients compared to Botulinum toxin $\mathrm{A}$ in combination with intermittent catheterization, especially if not only the urological properties of the treatments are taken into account. Spinal cord injury comprises a variety of coherent, physical problems. Therefore, management of multiple organ dysfunctions should be advocated. The Brindley procedure does not only enable continence and micturition, but also complete defecation or improvement of defecation pattern, penile erections, and reduction of autonomic dysreflexia and spasms. Patients become less dependent because they do not need assistance for intermittent catheterization anymore and can empty their bladder whereever and whenever. When the treatment options are discussed with a patient, this more extensive application of the Brindley procedure should be mentioned.

The Brindley procedure generally shows good clinical results for restoration of function in spinal cord injury patients with multiple organ dysfunction, including bladder, bowel, and erectile dysfunction. Moreover, the Brindley procedure improves quality of life $[20,21]$. However, it is not a procedure that is easy to apply in clinical practice. Firstly, not every patient is suited for the procedure and the success depends on selection of appropriate patients. Prerequisites are a complete spinal cord lesion since neurostimulation can cause pain in incomplete spinal cord lesions, an intact sacral motor neuron pathway enabling stimulation of the bladder, and a detrusor muscle that is capable to contract on stimulation. Secondly, a dorsal rhizotomy and implantation of a Brindley stimulator is complex and not a routine procedure for urologists and should be reserved for specialized centres. Thirdly, the technique is also prone to failures, including the external and implanted components. Analysis of the external components is easy to apply. Currently, a straightforward solution for analysis and revision of the implanted system without major surgery is not available in every country. This can be explained by national legislation with respect to certain aspects of the surgical procedure for revision of the implant, like burning the insulation of the implanted electrode cables. This excludes these patients from the thorough analysis of the implanted components and revision surgery to restore function of their stimulator. Nowadays, most patients have become increasingly familiar with intermittent catheterization and bowel rinsing. They accept the dysfunction of the stimulator more frequently because they remain continent due to their dorsal rhizotomy in combination with controlled emptying of their bladder and bowels.

A main issue for patients who consider a Brindley procedure is the irreversibility of the rhizotomy, and the possibility that future treatment options are not within reach anymore. Although SARS can restore penile erections after a rhizotomy, qualitative useful stimulation of erections is not possible in a substantial number of patients. Therefore, the dorsal rhizotomy should be replaced by a less invasive procedure to abolish detrusor overactivity. Continuous or conditional neuromodulation could be one of the solutions [22, 23]. Sacral posterior- and anterior- root stimulation combines neuromodulation and SARS without a rhizotomy of the dorsal roots for micturition. These new developments are, however, not generally introduced as a standard treatment. Sacral posterior and anterior root stimulation effectively suppress DO but do not result in complete emptying in all patients due to persisting detrusor-external sphincter dyssynergia [24]. This requires development of techniques that prevent backward stimulation when the anterior roots are stimulated to enable selective detrusor stimulation, like selective anodal block and high-frequency block [25-28].

\section{Conclusion}

The Brindley procedure shows good clinical results and improves quality of life. However, to remain a valuable treatment option for the future, the technique needs some adequate changes to enable analysis of the implanted parts, to improve revision techniques of the implanted parts, and to abolish the sacral dorsal rhizotomy.

\section{References}

[1] D. Sauerwein, "Surgical treatment of spastic bladder paralysis in paraplegic patients. Sacral deafferentation with implantation of a sacral anterior root stimulator," Urologe A, vol. 29, no. 4, pp. 196-203, 1990.

[2] M. Hohenfellner, J. Pannek, U. Bötel et al., "Sacral bladder denervation for treatment of detrusor hyperreflexia and autonomic dysreflexia," Urology, vol. 58, no. 1, pp. 28-32, 2001.

[3] P. E. V. Van Kerrebroeck, E. L. Koldewijn, P. F. Rosier, H. Wijkstra, and F. M. J. Debruyne, "Results of the treatment of neurogenic bladder dysfunction in spinal cord injury by sacral posterior root rhizotomy and anterior sacral root stimulation," Journal of Urology, vol. 155, no. 4, pp. 1378-1381, 1996.

[4] G. S. Brindley, C. E. Polkey, D. N. Rushton, and L. Cardozo, "Sacral anterior root stimulators for bladder control in paraplegia: the first 50 cases," Journal of Neurology Neurosurgery and Psychiatry, vol. 49, no. 10, pp. 1104-1114, 1986.

[5] L. Bauchet, F. Segnarbieux, G. Martinazzo, P. Frerebeau, and F. Ohanna, "Neurosurgical treatment of hyperactive bladder in spinal cord injury patients," La Neurochirurgie, vol. 47, no. 1, pp. 13-24, 2001.

[6] G. S. Brindley, "The first 500 patients with sacral anterior root stimulator implants: general description," Paraplegia, vol. 32, no. 12 , pp. 795-805, 1994.

[7] G. H. Creasey, J. H. Grill, M. Korsten et al., "An implantable neuroprosthesis for restoring bladder and bowel control to patients with spinal cord injuries: a multicenter trial," Archives of Physical Medicine and Rehabilitation, vol. 82, no. 11, pp. 1512-1519, 2001.

[8] G. Egon, M. Barat, P. Colombel, C. Visentin, J. L. Isambert, and J. Guerin, "Implantation of anterior sacral root stimulators combined with posterior sacral rhizotomy in spinal injury patients," World Journal of Urology, vol. 16, no. 5, pp. 342-349, 1998.

[9] O. Hamel, B. Perrouin-Verbe, and R. Robert, "Brindley technique with intradural deafferentation and extradural implantation by a single sacral laminectomy," La Neurochirurgie, vol. 50, no. 6, pp. 661-666, 2004. 
[10] J. Kutzenberger, B. Domurath, and D. Sauerwein, "Spastic bladder and spinal cord injury: seventeen years of experience with sacral deafferentation and implantation of an anterior root stimulator," Artificial Organs, vol. 29, no. 3, pp. 239-241, 2005.

[11] R. P. Macdonagh, W. M. Sun, R. Smallwood, D. Forster, and N. W. Read, "Control of defecation in patients with spinal injuries by stimulation of sacral anterior nerve roots," British Medical Journal, vol. 300, no. 6738, pp. 1494-1497, 1990.

[12] H. Madersbacher, J. Fischer, and A. Ebner, "sacral root stimulator (Brindley): experiences especially in women with neurogenic urinary incontinence," Neurourology and Urodynamics, vol. 7, no. 6, pp. 593-601, 1988.

[13] H. Madersbacher and J. Fischer, "Sacral anterior root stimulation: prerequisites and indications," Neurourology and Urodynamics, vol. 12, no. 5, pp. 489-494, 1993.

[14] L. Q. Robinson, A. Grant, P. Weston, T. P. Stephenson, M. Lucas, and D. G. Thomas, "Experience with the Brindley anterior sacral root stimulator," British Journal of Urology, vol. 62 , no. 6, pp. 553-557, 1988.

[15] M. Sarrias, F. Sarrias, and A. Borau, "The "Barcelona” technique," Neurourology and Urodynamics, vol. 12, no. 5, pp. 495496, 1993.

[16] D. Sauerwein, W. Ingunza, J. Fischer et al., "Extradural implantation of sacral anterior root stimulators," Journal of Neurology Neurosurgery and Psychiatry, vol. 53, no. 8, pp. 681684, 1990.

[17] B. Schurch, B. Rodic, and D. Jeanmonod, "Posterior sacral rhizotomy and intradural anterior sacral root stimulation for treatment of the spastic bladder in spinal cord injured patients," Journal of Urology, vol. 157, no. 2, pp. 610-614, 1997.

[18] H. E. van der Aa, E. Alleman, A. Nene, and G. Snoek, "Sacral anterior root stimulation for bladder control: clinical results," Archives of Physiology and Biochemistry, vol. 107, no. 3, pp. 248-256, 1999.

[19] P. E. Van Kerrebroeck, E. L. Koldewijn, and F. M. Debruyne, "Worldwide experience with the Finetech-Brindley sacral anterior root stimulator," Neurourology and Urodynamics, vol. 12, no. 5, pp. 497-503, 1993.

[20] J. M. Vastenholt, G. J. Snoek, H. P. J. Buschman, H. E. Van Der Aa, E. R. J. Alleman, and M. J. Ijzerman, "A 7-year follow-up of sacral anterior root stimulation for bladder control in patients with a spinal cord injury: quality of life and users' experiences," Spinal Cord, vol. 41, no. 7, pp. 397-402, 2003.

[21] F. M. Martens, P. P. den Hollander, G. J. Snoek, E. L. Koldewijn, P. E. van Kerrebroeck, and J. P. Heesakkers, "Quality of life in complete spinal cord injury patients with a Brindley bladder stimulator compared to a matched control group," Neurourology and Urodynamics, vol. 30, no. 4, pp. 551-555, 2011.

[22] J. Hansen, S. Media, M. Nøhr, F. Biering-Sørensen, T. Sinkjaer, and N. J. M. Rijkhoff, "Treatment of neurogenic detrusor overactivity in spinal cord injured patients by conditional electrical stimulation," Journal of Urology, vol. 173, no. 6, pp. 2035-2039, 2005.

[23] A. P. S. Kirkham, N. C. Shah, S. L. Knight, P. J. R. Shah, and M. D. Craggs, "The acute effects of continuous and conditional neuromodulation on the bladder in spinal cord injury," Spinal Cord, vol. 39, no. 8, pp. 420-428, 2001.

[24] A. P. S. Kirkham, S. L. Knight, M. D. Craggs, A. T. M. Casey, and P. J. R. Shah, "Neuromodulation through sacral nerve roots 2 to 4 with a Finetech-Brindley sacral posterior and anterior root stimulator," Spinal Cord, vol. 40, no. 6, pp. 272 $281,2002$.
[25] A. Boger, N. Bhadra, and K. J. Gustafson, "Bladder voiding by combined high frequency electrical pudendal nerve block and sacral root stimulation," Neurourology and Urodynamics, vol. 27, no. 5, pp. 435-439, 2008.

[26] G. S. Brindley and M. D. Craggs, "A technique for anodally blocking large nerve fibres through chronically implanted electrodes," Journal of Neurology Neurosurgery and Psychiatry, vol. 43, no. 12, pp. 1083-1090, 1980.

[27] N. J. Rijkhoff, H. Wijkstra, P. E. Van Kerrebroeck, and F. M. Debruyne, "Selective detrusor activation by electrical sacral nerve root stimulation in spinal cord injury," The Journal of Urology, vol. 157, no. 4, pp. 1504-1508, 1997.

[28] C. Seif, P. M. Braun, S. Bross et al., "Selective block of urethral sphincter contraction using a modified brindley electrode in sacral anterior root stimulation of the dog," Neurourology and Urodynamics, vol. 21, no. 5, pp. 502-510, 2002. 


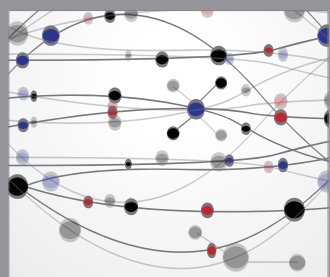

The Scientific World Journal
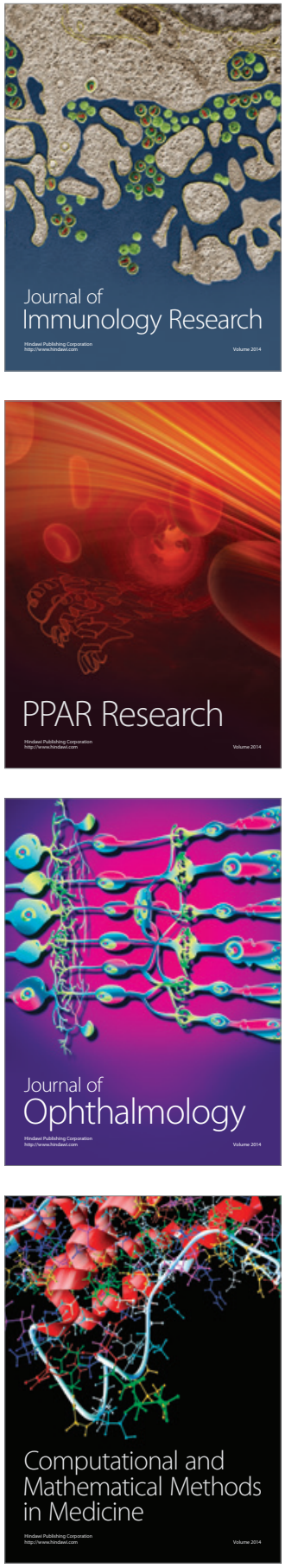

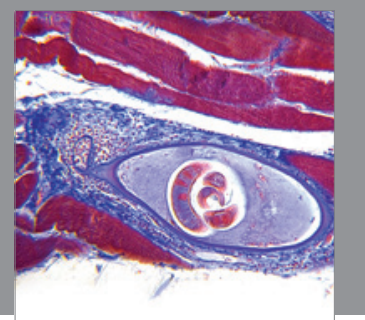

Gastroenterology

Research and Practice
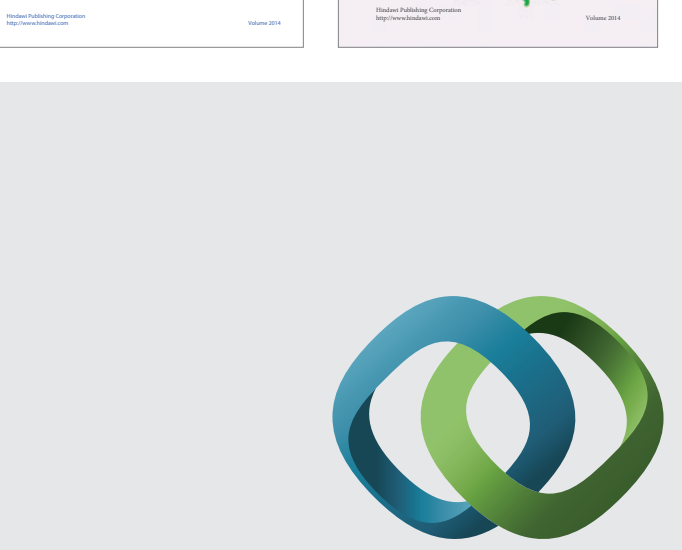

\section{Hindawi}

Submit your manuscripts at

http://www.hindawi.com
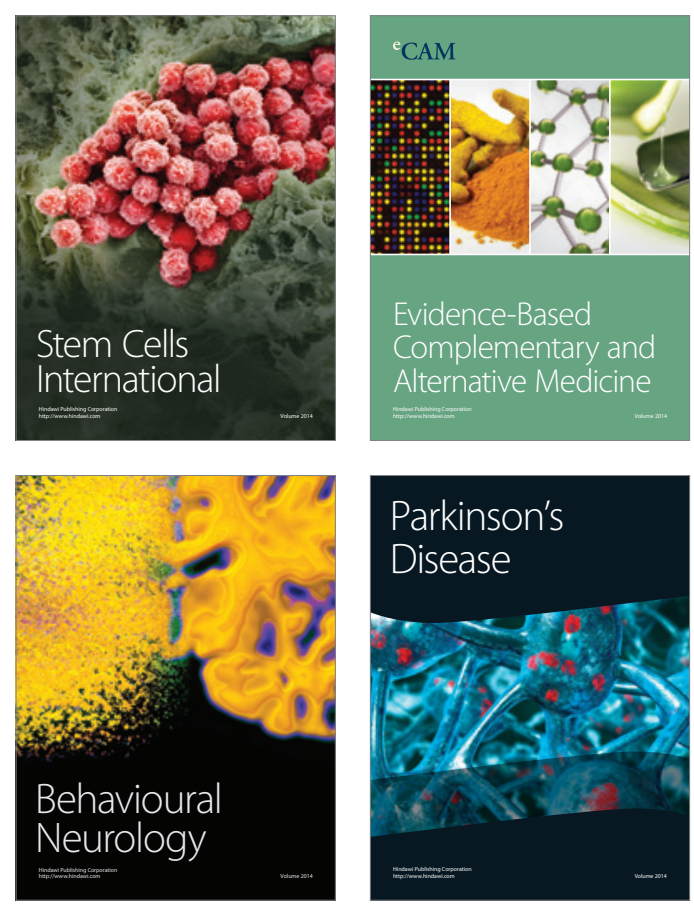

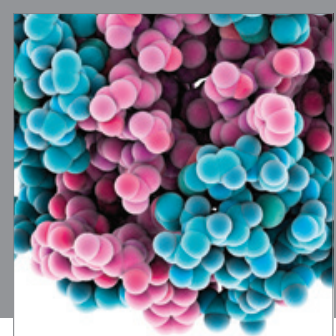

Journal of
Diabetes Research

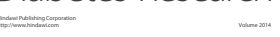

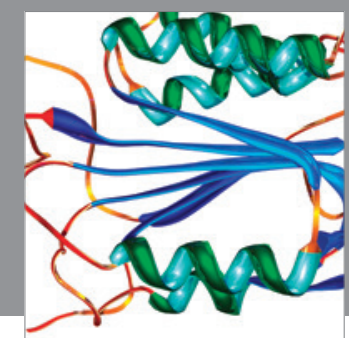

Disease Markers
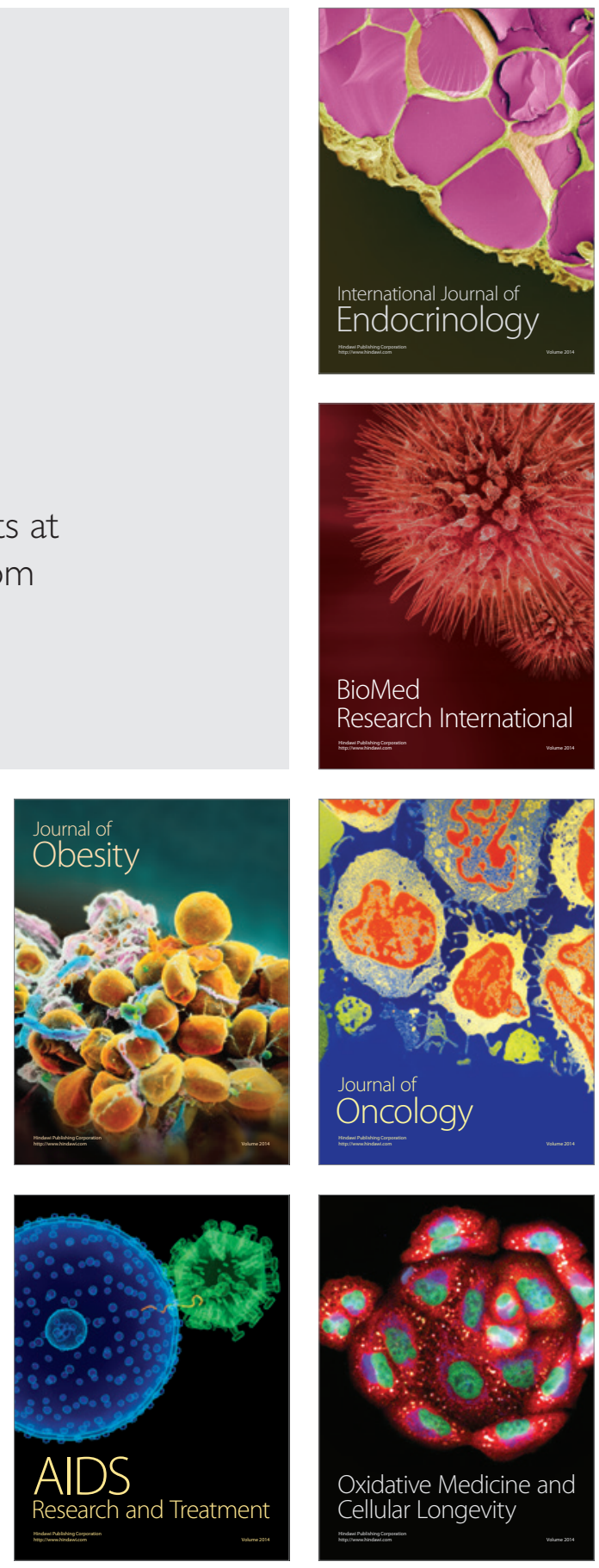